\title{
A new synthesis route for the preparation of the avocadofuran (2-hexadecylfuran)
}

\author{
Matthew C. Davis* and Thomas J. Groshens \\ Chemistry \& Materials Division, Michelson Laboratory, \\ Naval Air Warfare Center, China Lake, CA 93555, USA \\ E-mail:matthew.davis@navy.mil
}

DOI: http://dx.doi.org/10.3998/ark.5550190.p009.718

\begin{abstract}
A new synthetic route for the preparation of the insecticidal compound 2-hexadecylfuran is described in this study. The procedure starts from readily available furfuraldehyde and palmitic anhydride via two steps employing the Perkin reaction and resulting in a $25 \%$ overall yield. The method can be deemed as a practical and environmentally friendly route to prepare a potentially important class of insecticide.
\end{abstract}

Keywords: Furfuraldehyde, Perkin reaction, Lindlar catalyst, insecticide, avocadofurans

\section{Introduction}

The avocadofurans are a family of natural products isolated from avocado (Persia) which consist of 2-alkylfurans with varying degrees and sites of unsaturation (double and triple bonds) in the alkyl chain. ${ }^{1-3}$ Rodriguez-Soana and co-workers demonstrated that compounds structurally related to avocadofurans, saturated 2-alkylfurans with chain length of 14-18 carbon atoms, have inhibitory activity against larval growth of the agricultural insect beet army worm (Spodoptera exigua) and, therefore, such compounds could be useful insecticides in crop protection. ${ }^{4,5}$ The synthetic route employed by Rodriguez-Soana et al. to prepare 2-hexadecylfuran (1) is shown in Scheme 1. Furan is deprotonated at the alpha-position by reaction with butyllithium at cryogenic temperature, afterwards 1-bromohexadecane was added for a nucleophilic substitution reaction.

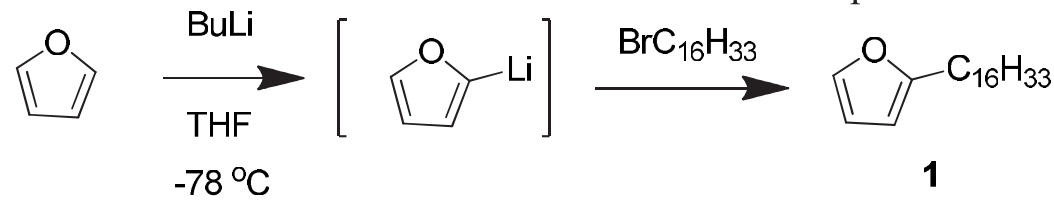

Scheme 1. Original synthesis of 2-hexadecylfuran by Rodriguez-Soana et al. 


\section{Results and Discussion}

As part of a study of the Perkin condensation, it was anticipated that the condensation of furfuraldehyde (2) with palmitic anhydride (3) might constitute a facile and inexpensive route to the insecticidal compound 2-hexadecylfuran (1) (Scheme 2). We now report the successful results of that investigation.

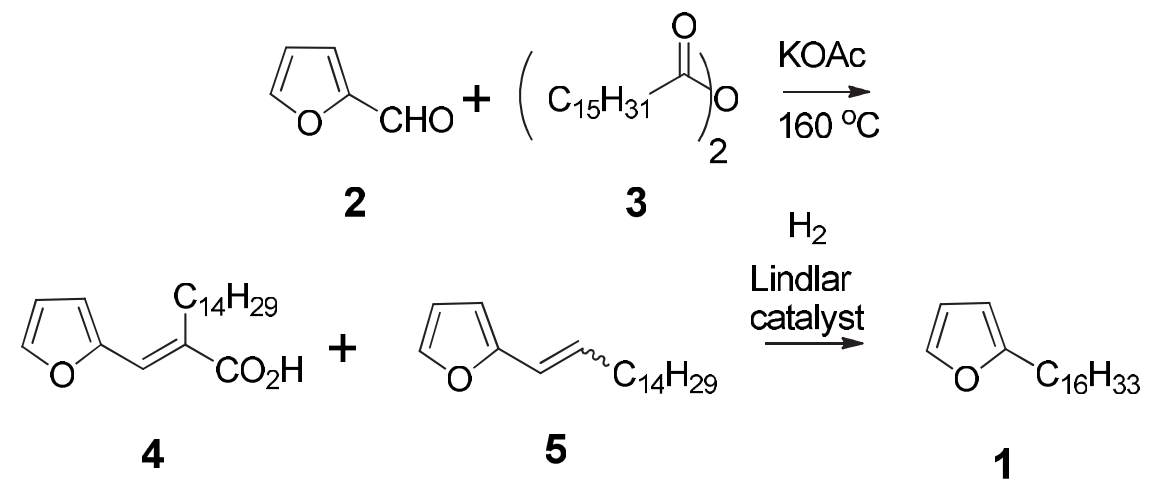

Scheme 2. New two-step synthesis of 2-hexadecylfuran by Perkin reaction followed by reduction.

Since the anhydride of palmitic acid is available only in small quantities for analytical purposes, it was conveniently prepared by reaction of palmitic acid with a 2.66 molar equiv. of acetic anhydride as dehydrating agent. ${ }^{6,7}$ Thus, after refluxing for four hours, distillation of the mixture at atmospheric pressure removed the excess acetic anhydride and by-product acetic acid and gave a 78\% yield of palmitic anhydride (3). Because palmitic acid and its anhydride have similar melting points, ${ }^{13} \mathrm{C}$ NMR was used to establish its structure and clearly showed the typical upfield shift of the carbonyl resonance of the anhydride (169.8 ppm) compared to that of the acid (180.5 ppm).

The Perkin condensation of 2 and 3 catalyzed by potassium acetate in a ratio of 1.85:1:1.09 was chosen owing to increased yields in similar reactions, (Scheme 2 ).${ }^{8-10}$ The mixture was heated in a controlled oil bath set to $160{ }^{\circ} \mathrm{C}$ for $4 \mathrm{hrs}$. The reaction quickly became dark brown in color and once the internal reaction temperature exceeded $110^{\circ} \mathrm{C}$, there appeared to be gas evolution. The work-up was complicated by the presence of large quantities of solids. The solids were collected, washed with ethyl acetate. Thin-layer chromatographic analysis of the filtrate on silica gel eluting with hexanes showed an unexpectedly fast moving non-polar component. It was isolated, purified by silica gel chromatography (elution with hexanes) and identified by ${ }^{1} \mathrm{H} N M R$ as a 1:1.85 mixture of cis- and trans-(2-furyl)hexadecene (5). In addition, the ${ }^{13} \mathrm{C}$ NMR showed twelve signals in the $\mathrm{sp}^{2}$-hybridized region confirming that two diastereomers were present. The yield of 5 was only $26 \%$ based on 3 . 
Evidently, under these conditions the anticipated product, 2-tetradecyl-3-(2-furyl)acrylic acid (4) underwent spontaneous decarboxylation to a considerable degree; two reports of Perkin condensation of benzaldehydes with stearic anhydride (another long chain fatty acid) make no mention of alkene products even though these reaction conditions were more vigorous $(36 \mathrm{~h}$ at 170 ${ }^{\circ} \mathrm{C}^{11}$ and $24 \mathrm{~h}$ at $210{ }^{\circ} \mathrm{C},{ }^{12}$ respectively). This suggests that the decarboxylation might have been facilitated by the presence of furan ring, an hypothesis currently under study. It is known that Perkin reaction of $\mathbf{2}$ with isobutyric ${ }^{13}$ and isopentanoic ${ }^{14}$ anhydrides yields alkenes as the major product under conditions similar to these and even 3-(2-furanyl)acrylic acid can be made to decarboxylate, although at higher temperatures $\left(>250{ }^{\circ} \mathrm{C}\right) .{ }^{15}$ The geometric isomerism of $\mathbf{5}$ is interesting to note since it clearly indicates that the intermediate acrylic acid $\mathbf{4}$ must have had trans configuration as proven in similar reactions. ${ }^{16}$ Other trans 2,3-disubstituted acrylic acids will undergo diastereospecific decarboxylation to cis alkenes by heating, with copper and quinolone for example (e.g. conversion of trans-1,2-diphenyl-acrylic acid to cis-stilbene). ${ }^{17}$ The proportion of thermodynamically favored trans $\mathbf{5}$ likely resulted from isomerization of cis $\mathbf{5}$ in the hot reaction mixture.

In order to confirm these conclusions, the original solid removed by filtration (vide supra) was treated slurried with a 1:1 mixture of ethyl acetate and hexanes. Evaporation of the extract followed by crystallization from hexanes allowed the isolation of a small amount of pure acrylic acid 4 in low yield (3.6\%) sufficient for X-ray crystal analysis of single crystals grown as colorless plates by slow evaporation of a toluene solution and established that $\mathbf{4}$ had the expected trans geometry about the double bond (the furan ring and tetradecyl chain share one side), Figure 1. Low thermal disorder was observed in the conformationally flexible alkyl chain since the experiment was carried out at $-100{ }^{\circ} \mathrm{C}$.

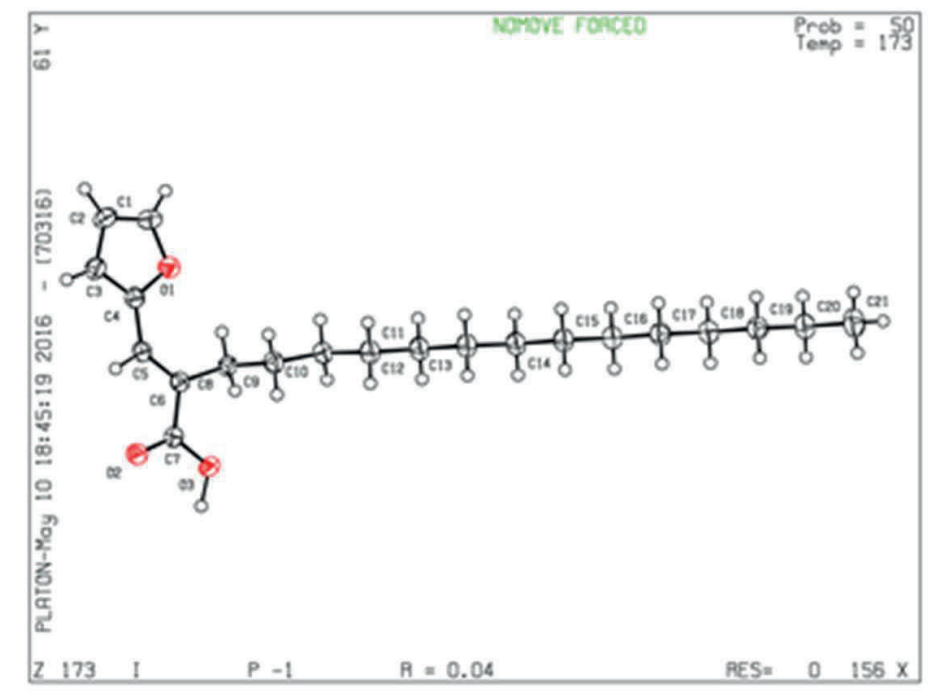

Figure 1. Thermal ellipsoid plot (50\%) of acrylic acid 4. 
The final step to $\mathbf{1}$ involving the selective catalytic reduction of the alkene mixture $\mathbf{5}$ was accomplished using Lindlar catalyst. Although the Lindlar catalyst is best known for the diastereoselective reduction of alkynes to cis-alkenes, the catalyst can bring about further reduction of alkenes to dihydro derivatives which may be prevented when used in conjunction with amine poisons. ${ }^{18}$ Other catalysts such as $\mathrm{Pd} / \mathrm{C}$ led to reduction of the furan ring of $\mathbf{5}$ as well as the double bond. The furan ring has been shown to be a structural feature, vital for biological activity. ${ }^{4,5}$

\section{Conclusions}

A two-step synthesis of the insect anti-feedant 2-hexadecylfuran (1) was accomplished starting from inexpensive furfuraldehyde (2) ${ }^{19-21}$ in $25 \%$ overall yield. Although the yield is low, the starting materials are inexpensive and are obtained from domestic agricultural sources.

\section{Experimental Section}

General. Mps were determined on a Meltemp II Electrothermal capillary melting point apparatus (Laboratory Devices, Holliston, MA) and are not corrected. $\mathrm{CDCl}_{3}$ was used for all NMR experiments carried out on a Bruker Avance II $300 \mathrm{MHz}$ spectrometer $\left({ }^{1} \mathrm{H}\right.$ at $300 \mathrm{MHz},{ }^{13} \mathrm{C}$ at 75 $\mathrm{MHz}$ ). NMR data (free induction decay signals) were processed using NUTS software from Acorn NMR (Livermore, CA). All ${ }^{1} \mathrm{H}$ spectra are referenced to tetramethylsilane $\left(\mathrm{Me}{ }_{4} \mathrm{Si}\right)$ and all ${ }^{13} \mathrm{C}$ spectra are referenced to the solvent. Thin-layer chromatographies (TLC) were carried out on aluminum foil backed, silica gel plates (2-25 micron particle size, $60 \AA)$ and elution with a mixture of hexanes/EtOAc. The plates were visualized using UV lamp $(254 \mathrm{~nm})$ and/or by staining with 10\% phosphomolybic acid in ethanol. Silica gel (grade 60, 60-200 micron, 60 $)$ for chromatography was obtained from Spectrum Chemical Mfg. Corp. (New Brunswick, NJ) and used as received. Palmitic acid, potassium acetate and acetic anhydride were obtained from SigmaAldrich (Milwaukee) and used as received. Furfuraldehyde (98\%) also obtained from SigmaAldrich was distilled under reduced pressure (60 torr) prior to use. Lindlar's catalyst was purchased from Sigma-Aldrich. All other solvents and reagents were acquired commercially and used as received. Elemental analyses were carried out by Atlantic Microlab Inc. (Norcross, GA).

Palmitic acid anhydride (3). A round-bottomed flask equipped with magnetic stirring bar and reflux condenser was charged with palmitic acid (50 g, $195 \mathrm{mmol})$ and $\mathrm{Ac}_{2} \mathrm{O}(53 \mathrm{~g}, 49 \mathrm{~mL}, 519$ mmol, 2.66 equiv). The mixture was vigorously stirred and heated to reflux for $4 \mathrm{~h}$. Afterwards, the condenser was exchanged for a distillation head and the volatiles were distilled at atmospheric pressure. The pot material solidified after cooling to ambient temperature. The crude product was recystallized from acetone to give 3 , soft, colorless platelets, yield $78 \%, 38 \mathrm{~g}, \mathrm{mp} 58-62{ }^{\circ} \mathrm{C}\left(\right.$ Lit. $^{22}$ $64{ }^{\circ} \mathrm{C}$ ); ${ }^{1} \mathrm{H}$ NMR: $\delta_{\mathrm{H}} 2.45$ (t, J 7.3 Hz, 4H), 1.66 (pent, J 7.9 Hz, 4H), 1.41-1.18 (m, 48H), 0.89 (t, 
$J 7.3 \mathrm{~Hz}, 6 \mathrm{H})$; ${ }^{1} \mathrm{H}$ NMR: $\delta_{\mathrm{C}} 169.83,35.50,32.14,29.91,29.90,29.88,29.85,29.79,29.61,29.57$, 29.40, 29.09, 24.45, 22.90, 14.31; Anal. Calcd for $\mathrm{C}_{32} \mathrm{H}_{62} \mathrm{O}_{3}$ (494.8): C, 77.67; H, 12.63\%. Found: C, 77.73; H, 12.71\%.

\section{2-Tetradecyl-3-(2-furyl)acrylic acid (4) and cis/trans 1-(2-furyl)hexadecene (5)}

A round-bottomed flask equipped with magnetic stir bar and reflux condenser was charged with 2 (10 g, $8.6 \mathrm{~mL}, 104 \mathrm{mmol}), 3$ (28.4 g, $57 \mathrm{mmol})$ and KOAc (6 g, $61 \mathrm{mmol})$. The vigorously stirred mixture was heated in an oil bath set to $160{ }^{\circ} \mathrm{C}$. After $4 \mathrm{~h}$, the dark brown reaction mixture was cooled to $\mathrm{rt}$ whereupon it solidified. The residue was slurried with EtOAc $(200 \mathrm{~mL})$ and the insoluble material was removed by suction filtration and stored for later recovery of the excess palmitic acid. The ethyl acetate filtrate was evaporated in vacuo to a brown-colored semi-solid. It was slurried and triturated with a 1:1 mixture of EtOAc and hexanes and the insoluble light brown solid was collected and the filtrate was saved. The solid was dissolved in hot hexanes and treated with decolorizing charcoal $(100 \mathrm{mg})$ and then filtered and evaporated to give 4, colorless needles, yield 3.6\%, $700 \mathrm{mg}$, mp. $82-84{ }^{\circ} \mathrm{C} ;{ }^{1} \mathrm{H}$ NMR: $\delta_{\mathrm{H}} 11.14\left(\mathrm{bs}, \mathrm{CO}_{2} \mathrm{H}\right), 7.52(\mathrm{~s}, 1 \mathrm{H}), 7.47(\mathrm{~s}, 1 \mathrm{H}), 6.6$ (d, J 2.6 Hz, 1H), 6.49 (bs, 1H), 2.68 (t, J 7.5 Hz, 2H), 1.50 (m, 2H), 1.25 (s, 22H), 0.88 (t, J 7.2 $\mathrm{Hz}, 3 \mathrm{H}) ;{ }^{1} \mathrm{H}$ NMR: $\delta_{\mathrm{C}} 174.03,151.99,144.51,130.08,126.95,115.54,112.29,32.17,30.09,29.95$ (overlapping signals), 29.91, 29.74, 29.61, 29.19, 28.05, 22.92, 14.32; Anal. Calcd for $\mathrm{C}_{21} \mathrm{H}_{34} \mathrm{O}_{3}+$ $0.125 \mathrm{H}_{2} \mathrm{O}$ (336.3): C, 74.90; H, 10.25\%. Found: C, 74.97; H, 10.12\%.

The filtrate saved from the second slurry and trituration with a 1:1 mixture of EtOAc and hexanes was evaporated in vacuo leaving a brown colored semi-solid which was dissolved in hexanes (200 $\mathrm{mL}$ ) with slight warming. The solution was passed through a cylindrical column (height $100 \mathrm{~mm}$, radius $35 \mathrm{~mm}$ ) of silica gel with elution with hexanes. The eluates containing the product were evaporated in vacuo to give 5, colorless oil, yield 26\%, $4.25 \mathrm{~g}$, 35:65 mixture of cis:trans geometric isomers; ${ }^{1} \mathrm{H}$ NMR: $\delta_{\mathrm{H}} 7.37$ (d, $J 1.7 \mathrm{~Hz}, 1 \mathrm{H}$, cis), 7.31 (d, $J 1.5 \mathrm{~Hz}, 1 \mathrm{H}$, trans), 6.39 (dd, $J 3.3$ and $1.8 \mathrm{~Hz}, 1 \mathrm{H}$, cis), 6.35 (dd, J 3.3 and $1.8 \mathrm{~Hz}, 1 \mathrm{H}$, trans), 6.25 (d, J $3.6 \mathrm{~Hz}, 1 \mathrm{H}$, cis), 6.18 (t, J 1.8 $\mathrm{Hz}, 2 \mathrm{H}$, trans) 6.17 (dt, $J 11.8$ and $1.6 \mathrm{~Hz}, 1 \mathrm{H}$, cis), 6.13 (d, J $3.5 \mathrm{~Hz}, 1 \mathrm{H}$, trans), 5.56 (dt, $J 11.9$ and $7.2 \mathrm{~Hz}, 1 \mathrm{H}$, cis), 2.44 (qd, $J 7.5$ and $1.8 \mathrm{~Hz}, 2 \mathrm{H}$, cis), 2.18 (qm, $J 6.9 \mathrm{~Hz}, 2 \mathrm{H}$, trans), 1.45 (pent, $J 7.1 \mathrm{~Hz}, 2 \mathrm{H}), 1.28$ (m, 22H), 0.89 (t, $J 6.9 \mathrm{~Hz}, 3 \mathrm{H}) ;{ }^{1} \mathrm{H}$ NMR: $\delta_{\mathrm{C}} 153.66,153.65,141.37$, $141.35,131.77,130.58,118.69,117.44,111.27,111.24,108.88,106.03,33.04,32.17,29.94$, 29.93, 29.89, 29.86, 29.77, 29.76, 29.66, 29.60, 29.53, 29.50, 29.44 22.93, 14.35; Anal. Calcd for $\mathrm{C}_{20} \mathrm{H}_{34} \mathrm{O}$ (290): C, 82.69; H, 11.80\%. Found: C, 82.52; H, 11.87\%.

2-Hexadecylfuran (1). A mixture of 5 (500 mg, $1.7 \mathrm{mmol}$ ), Lindlar catalyst (150 mg, $30 \mathrm{~mol} \%$ ) and EtOAc $(20 \mathrm{~mL})$ was shaken on a Parr ${ }^{\mathrm{TM}}$ hydrogenator under hydrogen at 15 torr. The reduction was complete in $40 \mathrm{~min}$. The suspension was filtered through diatomaceous earth (Celite ${ }^{\circledR} 541$ ) to remove the catalyst and the filtrate was evaporated in vacuo to give 1, colorless oil, yield 98\%, $490 \mathrm{mg} ;{ }^{1} \mathrm{H}$ NMR: $\delta_{\mathrm{H}} 7.30(\mathrm{~d}, J 1.4 \mathrm{~Hz}, 1 \mathrm{H}), 6.29(\mathrm{~m}, 1 \mathrm{H}), 5.98(\mathrm{~d}, J 2.9 \mathrm{~Hz}, 1 \mathrm{H})$, 2.62 (t, J 6.9 Hz, 2H), $1.64(\mathrm{~m}, 2 \mathrm{H}), 1.32(\mathrm{~m}, 2 \mathrm{H}), 1.27$ (s, 24H), 0.89 (t, $J 6.9 \mathrm{~Hz}, 3 \mathrm{H}) ;{ }^{13} \mathrm{C} \mathrm{NMR}$ : $\delta_{\mathrm{C}} 156.97,110.23,104.72,32.17,29.94,29.89,29.96$ (overlapping signals), 29.79, 29.61, 29.43, 28.27, 28.21, 22.92, 14.35; Anal. Calcd for $\mathrm{C}_{20} \mathrm{H}_{36} \mathrm{O}$ (292): C, 82.12; H, 12.41\%. Found: C, 82.26; $\mathrm{H}, 12.42 \%$. 


\section{X-Ray Structure Determination of 4.}

CCDC 1479181 (4) contains the supplementary crystallographic data which can be obtained free of charge from The Cambridge Crystallographic Data Centre via www.ccdc.cam.ac.uk/data request/cif, by e-mailing data request@ccdc.cam.ac.uk, or by contacting CCDC 12 Union Road, Cambridge CB2 1EZ, UK; fax: +44 1223336033.

\section{Acknowledgements}

This research was made possible by the generous financial support from the Strategic Environmental Research and Development Program (SERDP). The authors are indebted to Professor Emeritus J.-P. Anselme for kindly editing the manuscript. The authors would also like to thank Mary Ray and Mara Bowen of the Technical Library (NAWCWD) for assistance in collecting several literature citations. We also thank Professor Emeritus John Capinera of the University of Florida, Professor David Riley of the University of Georgia and Professor John Trumble of the University of California Riverside for information about Spodoptera and permission to use a photograph.

\section{References}

1. Weyerstahl P.; Marschall H.; Scora R. W. Flavour Fragrance J. 1993, 8, 201-207. http://dx.doi.org/10.1002/ffj.2730080407

2. Kashman Y.; Néeman I.; Lifshitz A. Tetrahedron 1969, 25, 4617-4631. http://dx.doi.org/10.1016/S0040-4020(01)83005-2

3. Kashman Y.; Néeman I.; Lifshitz A. Israel J. Chem. 1969, 7, 173-176. http://dx.doi.org/10.1002/ijch.196900029

4. Rodriguez-Saona C.; Maynard D. F.; Phillips S.; Trumble J. T. J. Agric. Food Chem. 2000, 48, $3642-3645$.

\section{http://dx.doi.org/10.1021/jf9910638}

5. Thomson W. W.; Platt K. A.; Trumble J. T.; Rodriguez-Soana C..S. Patent 6,133,313, 17 October 2000; Chem. Abstr. 2000, 133, 292321.

6. Wallace J. M. Jr.; Copenhaver J. E. J. Am. Chem. Soc. 1941, 63, 699-700. http://dx.doi.org/10.1021/ja01848a017

7. Albitzky A. J. Russ. Chem. Soc. 1899, 31, 103-106; Chem. Abstr. 1906, 246810.

8. Poonia N. S.; Sen S.; Porwal P. K.; Jayakumar A. Bull. Chem. Soc. Jpn 1980, 53, 3338-3343. http://dx.doi.org/10.1246/bcsj.53.3338

9. Ververkovà E.; Pacherovà E.; Toma Š. Chem. Papers 1999, 53, 257-259.

10. Johnson J. R. Org. Synth. 1945, 25, 51. http://dx.doi.org/10.15227/orgsyn.025.0051 
11. Krafft F.; Rosiny W. Ber. Dtsch. Chem. Ges. 1900, 33, 3576-3579.

http://dx/doi.org/10.1002/cber.190003303160

12. Rebrovic L.; Kilbarger A. C. U.S. Patent 5,279,759, 18 January 1994; Chem. Abstr. 1994, 120, 247827.

13. Baeyer A.; Tönnies, P. Ber. Dtsch. Chem. Ges. 1877, 10, 1364-1365. http://dx.doi.org/10.1002/cber.18770100226

14. Schaarschmidt, A.; Georgeacopol, E.; Herzenberg, J. Ber. Dtsch. Chem. Ges. 1918, 51, 10591074.

http://dx/doi.org/10.1002/cber.191805101130

15. Marckwald, W. Ber. Dtsch. Chem. Ges. 1887, 20, 2812-2818.

http://dx/doi.org/10.1002/cber.188702002141

16. Davis, M. C.; Parrish, D. A.; Harvey, B. G. Org. Prep. Proced. Int. 2013, 45, 304-313. http://dx.doi.org/10.1080/00304948.2013.798567

17. Taylor T. W. J.; Crawford C. E. J. J. Chem. Soc. 1934, 1130. http://dx.doi.org/10.1039/JR9340001129

18. Campos K. R.; Cai D.; Journet M.; Kowal J. J.; Larsen R. D.; Reider P. J. J. Org. Chem. 2001, 66, 3634-3635.

http://dx/doi.org/10.1021/jo015514a

19. Brownlee H. J.; Miner C. S. Ind. Eng. Chem. 1940, 40, 201-204. http://dx.doi.org/10.1021/ie50458a005

20. Miner C. S.; Trickey J. P.; Brownlee H. J. Ind. Eng. Chem. 1923, 27, 65-66. http://dx.doi.org/10.1021/ie50157a039

21. Zeitsch K. J. The Chemistry and Technology of Furfural and its Many By-products, Elsevier: Amsterdam, 2000.

22. Selinger Z.; Lapidot Y. J. Lipid Res. 1966, 7, 174-175. 